\title{
O CONCEITO DE AUTONOMIA APLICADO AO PROCESSO DE AQUISIÇÃO DE LÍNGUAS ESTRANGEIRAS NA ERA DA INFORMAÇÃO
}

\section{Erica de Cássia Modesto COUTRIM*}

- RESUMO: O uso de ferramentas da Internet para fins educacionais tem sido comumente associado, no ambiente escolar, à noção de autonomia. Esse conceito, no entanto, envolve elementos que extrapolam questóes metodológicas de aquisição de línguas estrangeiras engloba também questōes sociais, políticas e gnosiológicas. Por isso, procuraremos explorar o conceito de autonomia aplicado ao ensino e aprendizagem de LE por meio da Internet, partindo do princípio de que o indivíduo autônomo não pode ser determinado por outros indivíduos, e nem mesmo por aparatos tecnológicos, por mais avançados que sejam. Examinaremos, por meio de observação e questionários, porém, em que medida o uso de ferramentas de tecnologia comunicacional no ambiente Web pode contribuir para o processo de formaçáo de um indivíduo autônomo e, portanto, ativo, em seu próprio processo de aquisiçấo de uma língua estrangeira.

- PALAVRAS-CHAVE: Autonomia. Línguas estrangeiras. Internet. Aquisição linguística.

\section{Introdução}

O conceito de autonomia, aplicado às aulas de língua estrangeira nas quais são utilizadas ferramentas da Internet, está geralmente relacionado à participação dos alunos como agentes em uma atividade proposta pelo professor. Sua participação, no entanto, não obrigatoriamente o tirará de sua posição de receptor de conhecimento ou, nas palavras de Paulo Freire (1996), evitará a "educação bancária"1.

A diversas ferramentas tecnológicas, tais como aplicativos e softwares de aprendizagem, têm sido dada a responsabilidade de sanar problemas relacionados à aquisição de línguas estrangeiras - dentre eles, a ausência de identificação com os temas e conteúdos dos materiais didáticos, que são adotados pelas escolas e aplicados por

\footnotetext{
* USP - Universidade de São Paulo. Faculdade de Educação - Departamento de Linguagem e Educação. Sáo Paulo - SP - Brasil. 05508-040 - ericacoutrim@usp.br

1 Conceito criado por Paulo Freire para se referir ao tipo de ensino que desconsidera as características e conhecimentos do aluno, ou seja, que o trata como um mero receptor.
} 
professores, assumindo o aluno frequentemente um papel passivo, na última escala do processo (CASTELLS, 2015).

Dentro desse contexto, a Web seria capaz de possibilitar ao aluno a busca por informaçóes, além daquelas apresentadas pelo professor, e também o contato com situaçóes reais de uso da língua-alvo.

Quando o potencial de aplicação de ferramentas da Internet é visto da forma acima descrita, está se considerando que a produção de conhecimento só ocorre se informaçóes forem encontradas diretamente pelo estudante, e também de que o sentido, ou ainda, a aprendizagem significativa (AUSUBEL; NOVAK, 1980) só ocorrerá caso o aluno encene uma açáo relacionada à proposta educacional.

Uma proposta de aprendizagem em que o conhecimento ou o capital cultural do aluno (BOURDIEU apud PIES, 2012) é considerado, em que professor e aluno são vistos como elementos-chave e em constante transformação, e em que ambos são capazes de interpretar, produzir e transmitir conhecimento, pode produzir um ambiente autônomo de aprendizagem.

No caso do processo de aquisição de línguas estrangeiras (KRASHEN, 1982), a autonomia na aprendizagem (e também no ensino) não ocorrerá por meio da simples transferência de métodos, até então aplicados em meio físico, para o meio virtual.

\section{O (des) entendimento do conceito de autonomia}

A ainda existente distância entre teoria e prática acaba se tornando um espaço a ser preenchido por interpretações equivocadas e à aplicação de conceitos pedagógicos, filosóficos, sociológicos e políticos a serviço dos interesses (ou dificuldades) de instituições de ensino e empresas, que visam o lucro por meio dessas instituições. É o que vem ocorrendo com o conceito de autonomia, que vem sendo aplicado deliberadamente no cotidiano escolar para justificar a utilizaçáo de aplicativos e ferramentas da Internet em atividades educacionais. Como consequência, tem-se a redução do conceito à ação do aluno realizada no ambiente Web.

A ideia de autonomia, no entanto, vem sendo discutida desde a Grécia Antiga. Em todos esses séculos, teve sua significação aplicada à reflexão sobre a autodeterminação de unidades políticas, à superioridade do mundo das ideias, à busca pela felicidade, à liberdade da dependência e o poder para legislar, à liberdade espiritual e, finalmente, à pedagogia.

É com Rousseau (1973) que o conceito de autonomia assume um caráter diretamente pedagógico (diferentemente dos iluministas, que vincularam a autonomia à natureza, ou seja, a evidências empíricas). O filósofo francês defende que a educação deve servir para libertar o ser humano do "impulso puro". Segundo ele, o homem deve servir antes à razão, e não ao "amor a si mesmo" ou ao "amor próprio", o que configuraria heteronomia. Desligar-se da influência da natureza e estar em consonância com a liberdade e a autonomia de outros indivíduos guiaria o homem à liberdade e, portanto, à autonomia. 
Kant baseia-se nas ideias de Rousseau e propõe que a educação é pressuposto básico para a autonomia, mas afasta-se dele ao defender que o homem não deve se vincular a qualquer influência externa para se tornar autônomo, visto que a autonomia dependeria somente da vontade do ser racional, e não da natureza ou da autonomia de outros indivíduos. Para ele, a educação é o único meio para que o homem se diferencie dos demais seres na natureza, ou seja, somente a instrução seria capaz de tirar o homem da selvageria. Segundo ele, "o homem não pode tornar- se verdadeiro homem senão pela educação” (KANT, 1996b, p. 15). Assim, a educação teria o papel de guiar o homem à autonomia, afastando-o de seus impulsos selvagens, de modo que se torne hábil a fazer uso da própria razão.

Entre os pensadores modernos, temos de destacar a visáo de Piaget e de Paulo Freire a respeito do conceito de autonomia na educação. $\mathrm{O}$ primeiro, em termos sociocognitivos, e o segundo, por sua visão sociopolítica a respeito da autonomia na educação.

Piaget, como defensor da construção do conhecimento na criança, acentua que a autonomia é um estado anterior à heteronomia, visto que

A heteronomia sucede a autonomia: a regra do jogo se apresenta à criança náo mais como uma lei exterior, sagrada, enquanto imposta pelos adultos, mas como resultado de uma livre decisão, e como digna de respeito na medida em que é mutuamente consentida. (PIAGET, 1994, p.60).

Dessa forma, entende-se que o indivíduo autônomo é capaz de, por meio de sua maturidade intelectual, considerar um ponto de vista exterior ao seu por livre vontade, e não por uma determinação exterior, por meio do respeito recíproco, ou seja, numa relação harmônica entre autonomia moral e autonomia intelectual, segundo ele. Resumidamente, para Piaget, a autonomia é uma habilidade desenvolvida cognitivamente e socialmente, que torna o indivíduo capaz de tomar decisóes sobre o que é certo ou errado (moral) e o que é verdade ou falso (intelectual).

Paulo Freire, com sua obra Pedagogia da Autonomia, acrescenta um caráter políticosocial ao conceito de autonomia, conferindo ao indivíduo a responsabilidade de assumir um papel ativo no ambiente que o circunda, "[...] afinal, minha presença no mundo não é a de quem apenas se adapta, mas a de quem nele se insere. É a posição de quem luta para não ser apenas objeto, mas sujeito também da História." (FREIRE, 1996, p. 60). Dessa forma, o indivíduo autônomo é aquele que participa de seu próprio processo de aprendizagem, trazendo para a sala de aula suas próprias experiências, o "seu saber". Tal notação de participação do educando faz necessária a participação de um docente que tem consciência de que o ser humano é um ser inacabado, em constante processo de transformação, e que essa transformação também se dá pela interação com as experiências dos alunos. 
Se, na experiência de minha formação, que deve ser permanente, começo por aceitar que o formador é o sujeito em relação a quem me considero o objeto, que ele é o sujeito que me forma e eu, o objeto por ele formado, me considero como um paciente que recebe os conhecimentos-conteúdos-acumulados pelo sujeito que sabe e que são a mim transferidos. Nesta forma de compreender e de viver o processo formador, eu, objeto agora, terei a possibilidade, amanhã, de me tornar o falso sujeito da "formação" do futuro objeto de meu ato formador. É preciso que, pelo contrário, desde os começos do processo, vá ficando cada vez mais claro que, embora diferentes entre si, quem forma se forma e reforma ao formar e quem é formado forma-se e forma ao ser formado. É neste sentido que ensinar não é transferir conhecimentos, conteúdos nem formar é ação pela qual um sujeito criador dá forma, estilo ou alma a um corpo indeciso e acomodado. Não há docência sem discência, as duas se explicam e seus sujeitos, apesar das diferenças que os conotam, não se reduzem à condição de objeto, um do outro. Quem ensina aprende ao ensinar e quem aprende ensina ao aprender. (FREIRE, 1996, p.25).

A aplicação do conceito de autonomia em termos de aquisição de línguas estrangeiras no ambiente escolar náo pode ser reduzida à autonomia dada pelo professor ao aluno, por meio da realização de atividades no ambiente Web. Envolve, na verdade, inicialmente a autonomia do professor, que contribuirá e receberá retribuição no processo de formação do aluno autônomo, num processo cíclico em que se deve rever a relação dualista sujeitoobjeto, no que concerne a professor, aluno, Internet e língua estrangeira.

\section{Autonomia e método}

Desde a dominação dos sumérios pelos acádios (3000 até por volta de 2500 a.C.) (GERMAIN, 1993), o processo de ensino e aprendizagem de línguas estrangeiras vem ocorrendo por meio da transferência do conhecimento do professor para o aluno. Hoje, mais de 5000 anos, muito pouco de fato mudou ${ }^{2}$, apesar dos avanços científicos e desenvolvimento de novas abordagens a respeito do processo de aquisição de LE.

As reflexóes e avanços sobre a forma como se dá a aprendizagem ou (como tratamos aqui) a aquisição de línguas estrangeiras, levou ao desenvolvimento de diversas abordagens e métodos para o ensino de LE em escolas ou cursos de idiomas. O primeiro método que conhecemos foi desenvolvido em 1638 pelo tcheco Jan Amos Komensky. Comenius (como o chamamos em latim) escreveu a Didática Magna, na qual trata de elementos didáticos do ensino de LE e defende a utilização de jogos em sala de aula e condena a aplicação de castigos físicos (muito comuns na época).

Depois de termos passado pela Metodologia tradicional, direta, áudio-lingual e audiovisual, chegamos ao final do século XX e início do século XXI como

2 Vide a configuração das salas de aula e o papel do professor na maioria das escolas, naquela época e hoje. 
adeptos da metodologia comunicativa, desenvolvida por Hymes (1991) e baseada nas ideias de Chomsky (2015) sobre as estruturas inatas para aprendizagem de línguas, acrescentando a elas a relevância do contato social para o desenvolvimento da linguagem.

Apesar do último método basear-se essencialmente na comunicação, só isso não bastou para que o aluno saísse de sua função de "depósito de morfemas e sintagmas". Muitas editoras desenvolvedoras de materiais didáticos para o ensino de línguas estrangeiras continuam tratando a aquisiçáo como ensino, o professor como sujeito e o aluno como objeto, ainda que de forma mais sutil.

A aplicaçáo de atividades baseadas no método comunicacional não conferiu ao aluno ou ao professor (como procuramos aqui ressaltar) a autonomia possível e necessária para que a aquisição de uma LE, de fato, ocorra. A aplicação de um método que busque conferir ao aluno competência comunicativa, em detrimento do ensino direto de regras gramaticais, sintáticas e fonéticas, não garante um processo de aprendizagem autônomo, mas, sim, heterônomo, apesar de participativo, mesmo que na Internet.

\section{Autonomia e Internet}

O incômodo do professor e o desinteresse do aluno em idade escolar fizeram com que a Internet assumisse um papel de "emplastro Brás Cubas do ensino de línguas estrangeiras" 3 . Passamos a ver o simples uso de ferramentas da Internet como a forma revolucionaria de se conferir um caráter autônomo ao processo de ensino e aprendizagem de LE, resgatando, portanto, o interesse do aluno, solucionando, portanto, os problemas relacionados à motivação.

Uma análise pouco aprofundada detectará que a ideia acima é ingênua e simplista. Não pretendemos aqui afirmar que ferramentas da Internet não tem forte potencial para o desenvolvimento de um ambiente de ensino e aprendizagem autônomo. Pelo contrário, acreditamos que sim. No entanto, também cremos que a transferência de abordagens e métodos utilizados em ambiente físico (papel e lousa) para o ambiente virtual (Web) não o fará sozinha.

O processo de aquisição de línguas estrangeiras na Web pressupóe, primeiramente, a familiaridade de professores e alunos com as ferramentas da Internet. Esse pressuposto, no entanto, náo exige que o professor seja um especialista em tecnologia, e, tampouco, que o aluno o seja. Na verdade, faz-se necessário um despertar crítico para o uso de tais ferramentas nas aulas de línguas estrangeiras, ou seja, que a Internet sirva como meio para o processo de aquisição, não um fim. Dessa forma, professor e alunos não se tornam dependentes do interesse privado e do desenvolvimento de ferramentas específicas para o ensino e aprendizagem da LE, mas utilizam as ferramentas existentes, e que podem agregar valor ao processo de aquisiçãa.

3 Citação de ideia contida no livro Memórias póstumas de Brás Cubas de Machado de Assis. 
Observamos, no desenvolvimento desta pesquisa, que muitos sofrem pressão (e a insatisfação decorrente dela) para que ferramentas da Internet e outras tecnologias sejam aplicadas às suas aulas de idiomas. Diante disso, obtemos basicamente dois tipos de resultados: 1 . a reprodução de atividades de livros em papel para a Internet ou 2. uma miscelânea de métodos para que a tecnologia seja finalmente utilizada, conferindo um caráter pseudomoderno às aulas, de modo a conquistar os alunos.

$\mathrm{O}$ primeiro caso, obviamente, não fomenta a autonomia do aluno e, consequentemente, não resolve os problemas ligados à falta dela no ambiente escolar. O segundo caso, ainda pior, não só não fomenta a autonomia, mas pode causar grandes retrocessos em termos da participação ativa do aluno em seu processo de produção de conhecimento, uma vez que podem-se aplicar, num mesmo processo, atividades e métodos ultrapassados de ensino e aprendizagem de LE, somente para que o uso da tecnologia seja feito.

A criação de um ambiente autônomo para a aquisição de LE na Internet pressupóe, portanto, um professor autônomo, que seja capaz de contribuir para que os alunos também se tornem autônomos, ou seja, agentes de fato em seu próprio processo de aprendizagem, de modo a utilizarem a tecnologia como ferramenta e não como objetivo, o que nos faz lembrar do conceito de autonomia de Lalande (1999, p. 115) no Vocabulário Técnico e Crítico da Filosofia: "Etimologicamente autonomia é a condição de uma pessoa ou de uma coletividade cultural, que determina ela mesma a lei à qual se submete."

\section{A Internet e o pós-método}

Se o professor tem o papel de contribuir para a constituição de um indivíduo autônomo em relaçáo à sua própria aprendizagem, seu papel não se reduz (como comumente se pensa entre professores e instituiçóes de ensino). Seu papel, na verdade, é modificado e aprofundado. Trata-se agora de um professor que, não necessariamente precisa ser um especialista em tecnologia, mas, sim, um professor que faz uso crítico de seus conhecimentos, que se reconhece como um indivíduo inacabado em termos linguísticos (LE) e em termos sociológicos. Trata-se de um professor que compreende que sua função está diretamente vinculada ao desenvolvimento crítico e da autonomia de seus alunos. Para tanto, é preciso que esse professor seja também autônomo.

Ao tratarmos da formaçáo do professor, não podemos ignorar sua história. Precisamos falar de sua formação, mas, também, de seu histórico como aluno. O professor do início do século XXI, quase que invariavelmente, como procuramos mostrar acima, teve experiências pouco (ou nada) autônomas como aluno. No que diz respeito à línguas estrangeiras, seus professores eram considerados os detentores máximos de conhecimento ao qual eles tinham de ter acesso para reproduzir o mesmo conhecimento e aplicá-lo em sua vida, geralmente com interesses profissionais, ou seja, faltava autonomia no aprender e também na decisão de como se aplicar tais conhecimentos. 
$\mathrm{Na}$ universidade, foram ensinados os principais métodos e as principais abordagens para o ensino e aprendizagem de línguas estrangeiras. Discutiu-se pedagogia, filosofia e sociologia da educação, mas pouco se discutiu sobre o seu histórico como aluno. A esse professor ou a essa professora foi falado, nas salas de aula da universidade, sobre a importância da criação de um ambiente autônomo de aprendizagem, mas pouco se discutiu sobre sua própria autonomia enquanto aluno e enquanto professor. Hoje, exige-se ainda que esse profissional crie um ambiente autônomo com o uso da Internet para o ensino de LE, sem que ele tenha sido preparado para tanto, para ser autônomo, ou para ser autônomo na Web.

Em resposta à problemática da transformação do papel do professor de LE na atualidade (e podemos dizer, na era da informação), o professor Kumaravadivelu (2001, p.544-545, tradução nossa), da Universidade de San José, na Califórnia, propóe o seguinte:

Tenho sugerido que uma forma de definir a pedagogia pós-método é considerá-la sob três dimensóes: pedagogia da particularidade, pedagogia prática e pedagogia da possibilidade. Como pedagogia da particularidade, a pedagogia pós-método rejeita conjuntos de princípios e procedimentos genéricos voltados para objetivos genéricos. Pelo contrario, procura fomentar o avanço de uma pedagogia sensível ao contexto em que está inserida e que se baseia na compreensão de particularidades linguísticas, socioculturais e politicas. Já como pedagogia prática, a pedagogia pós-método rejeita a dicotomia artificial entre teóricos, que assumiram o papel de produtores de conhecimento, e professores, que assumiram o papel de consumidores de tais conhecimentos. Pelo contrário, a pedagogia prática procura romper com tal classificaçáo, habilitando e encorajando professores a teorizar a partir de sua prática e praticar o que foi teorizado por eles. E, por último, como pedagogia da possibilidade, a pedagogia pós-método rejeita a visão limitada que se tem sobre o ensino de idiomas que se limita aos elementos linguísticos obtidos em sala de aula.

Propóe-se, portanto, não a criação de um novo método, mas, sim, a reflexão para a transformação da atividade docente de línguas estrangeiras para lidar com os métodos e meios existentes, e aplicá-los de acordo com as experiências, necessidades e características de seus alunos. Tal abordagem agrega autonomia à prática docente e coloca as ferramentas da Internet a serviço da aprendizagem, liberta-a e liberta alunos e professores da heteronomia disfarçada de autonomia no processo de aquisição de LE na Internet.

\section{Agradecimentos}

Agradecimento à Isadora, por sua doçura e parceria desde o primeiro minuto de sua existência. E ao meu orientador, Vojislav Aleksandar Jovanic, pela liberdade intelectual e pela compreensão. 


\section{THE CONCEPT OF AUTONOMY APPLIED TO THE FOREIGN LANGUAGE ACQUISITION PROCESS IN THE AGE OF INFORMATION}

- ABSTRACT: The use of Internet tools for educational purposes has been commonly associated, in the school, with the notion of autonomy. This concept, however, involves elements that go beyond methodological issues regarding the acquisition of foreign languages in Web process - also encompasses social, political and gnostic issues. Therefore, we will try to explore the concept of autonomy applied to foreign languages teaching and learning process through the Internet, based on the principle that the autonomous individual can not be determined by other individuals, and even by technological devices, no matter how advanced they are. We will examine, however, to what extent the use of communication technology tools in the Web can contribute to the process of formation of autonomous and active individuals in their own process of acquiring a foreign language.

- KEYWORDS: Autonomy. Foreign languages. Internet. Language acquisition.

\section{REFERÊNCIAS}

ASSIS, M. Memórias póstumas de Brás Cubas. São Paulo: Saraiva, 2009.

AUSUBEL, D.; NOVAK, J. D. Psicologia educacional. Rio de Janeiro: Interamerica, 1980.

CASTELLS, M. Escola e internet: o mundo da aprendizagem dos jovens. Fronteiras do Pensamento, 12 jan. 2015. Disponível em: <https://www.youtube.com/watch?v=J4UUM2E_ yFo>. Acesso em: 08 jan. 2016.

CHOMSKY, N. Syntatic structures. Eastford: Martino Fine Books, 2015.

FREIRE, P. Pedagogia da autonomia: saberes necessários à prática educativa. São Paulo: Paz e Terra, 1996.

GERMAIN, C. Evolution de l'enseignement des langues: 5000 ans d'histoire. Paris: Clé International, 1993.

HYMES, D. Foundations in sociolinguistics. Philadelphia: University of Pensylvania Press, 1991.

KANT, I. Crítica da razáo pura. Tradução de Valério Rohden e Udo Valdur Moosburger. Sao Paulo: Nova Cultural, 1996a. (Os pensadores).

KANT, I. Sobre a pedagogia. Tradução de Francisco Cock Fontanella. Piracicaba: Ed. UNIMEP, 1996 b.

KRASHEN, S. Principles and practice in second language acquisition. Oxford: Pergamon, 1982. 
KUMARAVADIVELU, B. Language teacher education for a global society: a modular model for knowing, analyzing, recognizing, doing, and seing (ESL \& Applied linguistics professional series). Oxford: Routledge, 2011.

LALANDE, A. Vocabulário técnico e crítico da filosofia. 3. ed. São Paulo: Martins Fontes, 1999.

PIAGET, J. O juízo moral na criança. São Paulo: Martins Fontes, 1994.

PIES, N. Processo educacional em Pierre Bourdieu. Revista Espaço Acadêmico da Universidade Estadual de Maringá, Maringá, n.134, p. 40-46, jul. 2012.

ROUSSEAU, J. Do contrato social. Tradução de Lourdes Santos Machado. São Paulo: Abril Cultural, 1973. (Os Pensadores; 24).

Recebido em março de 2016

Aprovado em agosto de 2016 
